\title{
REVIEW
}

\section{A Biopsychosocial Model for the Management of Patients With Sickle-Cell Disease Transitioning to Adult Medical Care}

Lori E. Crosby • Charles T. Quinn • Karen A. Kalinyak

To view enhanced content go to www.advancesintherapy.com

Received: January 14, 2015 / Published online: April 2, 2015

(c) The Author(s) 2015. This article is published with open access at Springerlink.com

\section{ABSTRACT}

The lifespan of patients with sickle-cell disease (SCD) continues to increase, and most affected individuals in high-resource countries now live into adulthood. This necessitates a successful transition from pediatric to adult health care. Care for transitioning patients with SCD often falls to primary care providers who may not be fully aware of the many challenges and issues faced by patients and the current management strategies for SCD. In this review, we aim to close the knowledge gap between primary care providers and specialists who treat transitioning patients with SCD. We describe the challenges and issues encountered by these patients, and we propose a biopsychosocial multidisciplinary approach to the management of the identified

Electronic supplementary material The online version of this article (doi:10.1007/s12325-015-0197-1) contains supplementary material, which is available to authorized users.

L. E. Crosby $(\varangle)$ · C. T. Quinn · K. A. Kalinyak Cincinnati Children's Hospital Medical Center, Cincinnati, OH, USA

e-mail: lori.crosby@cchmc.org

L. E. Crosby · C. T. Quinn · K. A. Kalinyak Department of Pediatrics, College of Medicine, University of Cincinnati, Cincinnati, OH, USA issues. Examples of this approach, such as transition-focused integrated care models and quality improvement collaboratives, with the potential to improve health outcomes in adulthood are also described.

Keywords: Adolescent; Pediatric; Sickle-cell disease; Transition to adult care; Young adult

\section{INTRODUCTION}

Sickle-cell disease (SCD) refers to a group of genetic disorders caused by an abnormal hemoglobin molecule, sickle hemoglobin, which polymerizes upon deoxygenation. The key pathophysiological features of SCD are chronic hemolytic anemia and vaso-occlusion by abnormal red blood cells, but it is a systemic disease that affects all organs. Over the last few decades, there has been a significant decrease in mortality for children with SCD, resulting in an increased lifespan [1-5] (Fig. 1). In the United States, mortality has significantly decreased by $61 \%$ in infants aged $<1$ year, by $67 \%$ in children aged 1-4 years, and by $22-35 \%$ in children aged 5-19 years from 1979 to 1998 and 1999 to 2009 


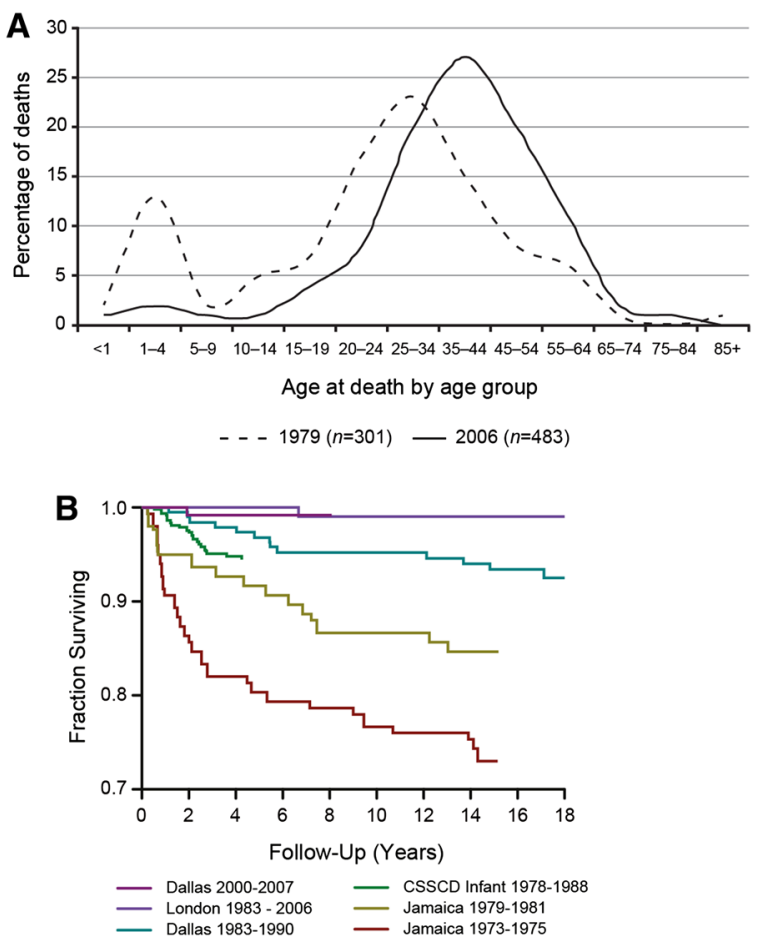

Fig. 1 Improving survival of children with sickle-cell disease. a Age at death for individuals with sickle-cell disease in 1979 and 2006 [4]. b. Overall survival estimates for children with $\mathrm{HbSS}$ and $\mathrm{HbS} \beta^{0}$-thalassemia estimated from large, newborn cohorts in the United States, United Kingdom, and Jamaica [5]. Reprinted from Hassell [4], with permission from Elsevier, and republished with permission of American Society of Hematology from Improved survival of children and adolescents with sicklecell disease. Quinn et al. [5]; permission conveyed through Copyright Clearance Center, Inc. CSSCD Cooperative Study of Sickle Cell Disease

[1]. Overall, the pediatric SCD mortality rate in the United States has decreased significantly by $3 \%$ each year from 1979 to 2005, so most children with SCD now live into adulthood [2, 5]. Contemporary survival data for adults with SCD are lacking, but calculations from the Jamaican SCD cohort suggest a median survival of 53.0 years for men and 58.5 years for women with homozygous SCD (commonly referred to as sickle-cell anemia or HbSS) [6].

Several factors have contributed to this increase in lifespan. Newborn screening, which has been universally implemented in the
United States and the United Kingdom, has allowed early, presymptomatic diagnosis and preventive management $[7,8]$. Prophylactic penicillin has been shown to significantly reduce the risk of invasive pneumococcal infection in children with SCD [9]. Effective (protein-conjugate) vaccinations against Haemophilus influenzae type b and Streptococcus pneumoniae have also decreased fatal infections caused by encapsulated organisms [3, 10]. Hydroxyurea treatment $[11,12]$ and improvements in general supportive care for acute illnesses have further improved survival for those with SCD [5].

Consequently, the burden of SCD-related mortality in high-resource countries has shifted to young adults, so a successful transition from pediatric to adult care is now critically important [5, 13-16]. Within the first 5 years of transition, there is an increased risk of death [5] probably due to a combination of factors, including different health care utilization patterns and increased likelihood of chronic organ damage from SCD. Furthermore, the care of the transitioned patient with SCD often falls to primary care providers (e.g., internists, family practitioners, and internal medicine/pediatric providers) who may not be as familiar with SCD as are pediatric hematologists [17]. In this review, we describe the challenges and issues for transitioning patients with SCD. Specifically, a biopsychosocial, multidisciplinary approach to the management of these issues is proposed. Examples of this approach, such as transitionfocused integrated care models and quality improvement collaboratives, with the potential to improve health outcomes in adulthood are also described.

The analysis in this article is based on previously conducted studies, and does not involve any new studies of human or animal subjects performed by any of the authors. 


\section{BIOPSYCHOSOCIAL MODEL FOR TRANSITION OF CARE}

The goal of an organized, well-coordinated transition to adult health care should be to assist each young person with SCD in attaining his or her maximum health potential [18]. However, acquiring autonomy and independence while learning to live with SCD is often difficult for young adult patients [1315]. Thus, a biopsychosocial, multidisciplinary approach to management is recommended. In this approach, health care providers from different disciplines (e.g., medicine, nursing, psychology, and social work) collaborate in a coordinated fashion to address the physical, psychological, and social factors associated with the overall goal of improving health outcomes [19-21]. A multidisciplinary approach to care is widely accepted with the increased understanding of the interplay between the biological, psychosocial, and sociological factors in SCD. These challenges, in addition to differences in the delivery of health care between pediatric and adult systems, support such an approach.

\section{Biological- or Disease-Related Factors}

Patients with SCD experience a spectrum of complications, such as acute or chronic pain, chronic hemolytic anemia, and ongoing organ damage [22, 23], including the brain, kidney, spleen, lungs, heart, and eyes. SCD-related organ damage is often chronic and increasingly manifests with age [22]. These cumulative effects and their treatments can result in additional comorbidities such as asthma, avascular necrosis of the long bones, restrictive lung disease, retinopathy, pulmonary hypertension, transfusion-related iron overload, cardiac dysfunction, and renal dysfunction. All of these complications have important implications for the management of patients transitioning to adult care.

Various SCD-associated signs and symptoms should be assessed and managed in the transitioning young adult [22, 24-31]. Please refer to the guidelines published by the National Heart, Lung, and Blood Institute (NHLBI) for comprehensive details on the management of patients with SCD [24]. Many of these comorbidities require intensive or regular monitoring (e.g., proteinuria and hypertension [29] or yearly ophthalmologic examinations [24]), maintenance of comprehensive and timely medical records (e.g., for blood transfusions, iron overload, and alloimmunization [24]), other specialist care (e.g., for retinopathy [24], nephropathy [29], or chronic pain [24]), patient education, and self-management support (e.g., priapism [24], leg ulcers [22], and prescription refills [14]). Treatment of some conditions can further exacerbate other symptoms (e.g., use of corticosteroids for asthma may contribute to vaso-occlusive events [24]). For these reasons, a multidisciplinary approach is indicated for the management of adolescents with SCD transitioning into adult care.

\section{Focus on Neurological Factors: Stroke and Silent Cerebral Infarct}

The progressive nature of SCD and SCD-related cognitive limitations have been identified as factors that significantly complicate the transition process and prevent optimal outcomes for young adults with SCD. Brain injury, a biological issue with direct psychological and sociological ramifications, can affect the success of transition. Patients with SCD are at high risk of overt stroke, which occurs in approximately $11 \%$ of 
children $<20$ years of age who have sickle-cell anemia but do not have the benefit of primary stroke prevention programs [32]. Transcranial Doppler ultrasonography (TCD) screening is the standard screening procedure for primary stroke prevention in pediatric patients with sickle-cell anemia [33]. When TCD suggests a high risk of stroke, long-term transfusions or hydroxyurea are indicated [32, 34-36]. Transfusions may need to be continued indefinitely, or may be stopped after some period of time when the risk of stroke is perceived to be lower [24]. Transfusions are costly and carry the risk of iron overload and alloimmunization [24, 34]. Transfusion-related iron overload is managed primarily with chelation therapy (deferasirox, deferoxamine, or deferiprone), and can be limited by partial or automated exchange transfusions [24]. Adherence with chelation therapy is often suboptimal in patients with SCD because of issues associated with the mode of administration (e.g., oral ingestion of chalky substance or subcutaneous injections). A comprehensive program to monitor and treat iron overload and to educate patients is needed [24], but this may be difficult if transitioning patients are mainly using emergency services. For these reasons, chronic transfusion therapy may be stopped after transition to adult medical care. Whether this is the best course of action or simply the most expedient is not clear, especially because the risk of stroke increases during adult life [37].

Treatment with hydroxyurea has been proposed as an alternative to chronic transfusions for primary stroke prevention, and was tested in children in the phase 3, randomized Transfusions Changing to Hydroxyurea (TWiTCH) trial sponsored by the NHLBI (ClinicalTrials.gov number, NCT01425307) [36]. Although not yet published in final, peer-reviewed form, the results are reported to show that hydroxyurea is not inferior to blood transfusions (using only TCD velocity as the outcome) in children with SCD who are at high risk for stroke by TCD criteria. If the approach of the TWiTCH trial is adopted by the medical community, the number of patients with SCD who are transitioned to adult care with iron overload may decrease as hydroxyurea use increases.

Silent cerebral infarction (SCI) occurs more frequently than overt stroke (37\% of patients aged at least 14 years) [38], but the risk of both increases with age [38-40]. Data from the Cooperative Study of Sickle Cell Disease showed that the chances of having a first stroke in patients with sickle-cell anemia were $11 \%$ and $24 \%$ by the age of 20 and 45 years, respectively [39]. In the same cohort, $24.5 \%$ of those with SCI at baseline developed new or more extensive SCI during a mean follow-up period of 5.2 years [41]. Even though evidence for the prevalence of SCI in adults is limited [40, 42], $50 \%$ of adult patients with SCD with normal baseline neurologic examination and no history of stroke or transient neurologic events had SCI, and 25\% had progressive abnormalities on magnetic resonance imaging (MRI) during a 3.7-year follow-up [43]. Both stroke and SCI are often associated with neurocognitive morbidity [38, 40,44], and this decline in neurocognitive function may become increasingly apparent in adulthood [40]. Impaired neurocognitive function has also been observed in seemingly neurologically intact individuals and appears to be associated with anemia and age [42].

Results of the phase 3, multicenter, randomized Silent Cerebral Infarct Trial (ClinicalTrials.gov number, NCT00072761) sponsored by the National Institute of Neurologic Disorders and Stroke were published in 2014. This study reiterated that 
chronic transfusions, compared with observation, for children with SCI significantly reduced the development of new or progressive silent and overt cerebral infarction and improved quality of life in children with SCI compared with observation alone [45]. If the approach of this trial is adopted by the medical community, the number of patients with SCD who are transitioned to adult care with iron overload may increase. It is not known whether hydroxyurea is equally as effective in reducing the development of SCI.

Decline in neurocognitive function, which appears to be associated with SCI, household income, highest academic attainment of head of household, hemoglobin oxygen saturation, and degree of anemia, can further impact the management of patients transitioning to adult care, both by delaying transition and impeding young people from taking full responsibility for their chronic condition [46]. Assessment of neurocognitive impairment is essential but difficult because it is generally not detected by imaging and other routine diagnostic methods [22], and deficits may be present in seemingly neurologically intact patients. Systematic follow-up of such patients is needed, especially because the rate of strokes in patients with SCD peaks between the ages of 35 and 64 years [37]. Comprehensive screening for stroke in adults with SCD should also evaluate risk factors such as blood pressure [24, 47].

\section{Psychosocial Factors}

The transition to adulthood is a critical juncture [48] as young adults navigate rapid social and psychological changes in their journey toward independence [15]. This process is often more difficult in those with SCD. Adolescents with SCD may require support from their families and medical staff to assume increasing responsibility for the management of their chronic condition [15]. Some adolescents (aged 13-21 years) have expressed concerns about leaving their familiar pediatric health care providers and going to new adult care providers who might not understand their needs [49], as well as having limited information about the transition process and adult health care programs [50]. In addition, young adults may not be capable of effectively advocating for themselves in the adult health care system. As a result, family members may accompany young adults to visits. Providers are encouraged to include family members when appropriate as they may play an essential role in promoting adherence to the treatment plan.

Adolescents with SCD are often poorly prepared for the transition to adult care, even though they acknowledge the importance of this transition. A survey of 70 patients at a pediatric SCD center found high scores of perceived importance of the transition but low scores for transition readiness, particularly in the areas of previous thoughts about transitioning, knowledge of care steps, anticipated difficulty with transitioning, and interest in transitioning [51]. Patients with SCD who had previously transitioned to adult health care reported that they received little preparation and that the transition was based strictly on age rather than readiness or need [52].

Medical complications and comorbidities associated with SCD can exacerbate social, emotional, and behavioral difficulties that may also impede the transition process [53]. For example, successful pain management is essential as patients transition to adulthood, as this will affect their ability to cope with SCD throughout their remaining lifetime [24]. Chronic pain can be difficult to manage due to the complex involvement of sensation, 
emotion, cognition, memory, and context. In addition, chronic pain can be physically and psychologically debilitating [24], which can hamper the transitioning process, especially for patients with inadequate support and education. A majority of primary care providers reported being uncomfortable managing chronic pain in transitioning patients with SCD [17]; however, there is a need for continuity of care and good patient/physician communication during the transition phase to provide adequate pain management. Pain assessment requires an understanding of a patient's chronological age, developmental stage, functional status, cognitive ability, and emotional state [24]. Treatment should be tailored to a patient's needs, which necessitates a detailed understanding of the pain experienced [24]. Individuals who experience chronic pain require intense education to understand that the goals of therapy for chronic pain (i.e., to minimize pain, increase pain coping skills, and maintain maximal social and physical functioning) are different than those for acute pain [24].

In addition to the pharmacologic treatment of pain, non-pharmacologic interventions such as physical therapy, cognitive behavioral therapy, or rehabilitation may also be required $[24,54,55]$. Patients may be treated with hydroxyurea to reduce the frequency of pain episodes [24]; however, this modality is underutilized due to a lack of awareness and concerns about toxicity and treatment adherence [56, 57]. Hydroxyurea therapy requires careful monitoring during treatment initiation along with blood counts every 4-8 weeks once a stable, maximally tolerated dose is reached [24]. Treatment adherence to hydroxyurea is often challenging, as it is with any long-term medicine, because patients may not feel better until several months after initiation. A discussion about barriers and facilitators to adherence in combination with a monitoring plan is recommended $[56,57]$.

Many factors can impact patient adherence not only to medication, but also to other treatments, referrals to specialists, and clinic attendance [13, 56, 57]. Financial difficulties, skepticism of the health care system, and barriers to access can lead to non-adherence $[13,24]$. Adherence may be improved through patient education and intervention, as well as stronger patient/physician relationships and communication $[13,53]$. The latter might be achieved through initiatives, such as the pediatric care team introducing patients to physicians responsible for adult care, or through mobile phone or e-mail contact between young adult patients and nurses [13, 58]. Referrals to psychologists and others who specialize in the promotion of treatment adherence may be the best option for some patients [15].

Young adults with mild SCD tend to skip follow-up with specialists, especially if complications are asymptomatic (e.g., nephropathy or retinopathy) [24]. As a result, adults and adolescents in transition tend to rely heavily on emergency care rather than following a developed plan with specific goals [15], as exemplified by the high rates of acute care utilization in young adults with SCD (3.61 per patient per year; 95\% confidence interval 3.47-3.75) compared with the general SCD population (2.59 per patient per year; 95\% confidence interval 2.53-2.65) [59]. Rehospitalization rates in patients with SCD were also highest among those aged 18-30 years [59]. This poor continuity of care can potentially have a negative impact on health and psychosocial outcomes in young adults with SCD [15]. 


\section{Sociological Factors}

Sociological issues affecting adolescents with SCD transitioning to adult care can include changes in insurance coverage [15], schooling [60], and employment opportunities [61]. Many young adults change or lose the insurance coverage that was in place during their childhood, which can jeopardize their continuity of care $[15,60]$, and it is estimated that $29 \%$ of young adults (18-24 years) with SCD are uninsured [14]. Access to necessary insurance coverage for preventive care and assistance with medication costs is now provided in the United States under the Patient Protection and Affordable Care Act (PPACA) [62]. It will be essential to collect data to determine if this improves access to health insurance for this population.

For many young adults, painful events or hospitalizations may lead to frequent school absences and difficulty in maintaining passing grades [60]. These issues may be further exacerbated by neurocognitive morbidity, such as impairments in selective attention, working memory, and processing speed, all of which have been associated with stroke and SCI in pediatric patients with SCD [40]. Securing or keeping employment can be impeded due to chronic pain, physical disabilities, acute pain episodes, or other complications that can result in hospitalization [60], and rates of unemployment are high for adults living with SCD, although this may be affected by other demographic and psychosocial factors [61]. Among adults with SCD, women are approximately three times more likely to be employed than men [61], and are more likely to be employed if they did not perceive SCD to interfere with maintaining gainful employment; however, those who are more assertive in advocating for sick leave or work accommodations for their disease may be perceived negatively by employers and coworkers [61]. Limited educational achievement and employment rates, along with the resultant lower income, may thus impact access to health care for some patients and further supports the need for a biopsychosocial, multidisciplinary approach to care.

\section{Differences in Health Care Delivery between Pediatric and Adult Systems}

Comprehensive care programs exist for pediatric patients with SCD, but there remains a lack of available, trained providers for adults [15]. Pediatric SCD care centers have established better coordinated support systems compared with adult SCD care centers, which have fewer interdisciplinary services and higher expectations of self-management [15]. Pediatric patients often receive care through a dedicated medical home that has a multidisciplinary SCD clinic to coordinate care with the child's primary care pediatrician, or that is run by a primary care pediatrician who makes referrals to SCD specialists for comprehensive evaluations and management of life-threatening complications [63].

In the United States, the current approach for managing adults with SCD tends to default to primary care providers who do not specialize in the treatment of SCD, making it difficult for transitioning patients to find physicians who are comfortable with and have the resources to manage their condition. These primary providers may instead make referrals to or consult with hematologists as insurance and finances allow [13]. In a national survey conducted in the United States, only $38 \%$ of general pediatricians and $51 \%$ of general internists thought it would be easy for young 
adult patients with a childhood-onset chronic disease to find a general internist who would be willing to oversee their primary health care needs [64]. For both internists and pediatricians, care coordination and effective direct communication between subspecialists are positively associated with higher quality of care during the transition phase, although it may not always be adequate [64].

Management of transitioning patients with SCD contrasts with management of other chronic childhood diseases, such as cystic fibrosis or hemophilia, for which adult patients are more likely to receive diseasespecific, center-based, comprehensive, multidisciplinary care in specialized treatment centers [13]. Moreover, patient registries that help monitor outcomes and treatment effectiveness in patients with hemophilia [13] have only recently been established in SCD [65].

The US reimbursement system within adult care may limit the willingness of specialists (e.g., hematologists/oncologists) to see adolescent and adult patients with SCD whose care may be more time intensive, but far less lucrative, than that of cancer patients [13]. This is yet another reason that the primary care of adults with SCD often defaults to general internists [13]. Under the PPACA, adults with SCD are likely to have greater access to primary and specialty care services in the future [62].

\section{BIOPSYCHOSOCIAL, MULTIDISCIPLINARY MODELS FOR TRANSITION OF CARE}

Multidisciplinary and biopsychosocially oriented transition programs can provide ageappropriate treatment and continuity of care from pediatric to adult facilities [13-16, 24]. In these programs, the transition occurs within the larger, holistic context of the life of the young adult (Fig. 2) [15, 66]. The transition plan needs to be flexible enough to accommodate most individual requirements, thereby allowing patients to explore their independence and develop skills in managing their chronic disease [13]. Discussions about transition should occur before transferring care [13, 24], as this allows time for physicians to address patients' and parents' fears or uncertainties and redirect negative feelings about the transition process [16]. Participants can benefit from training in effective communication skills, financial planning, self-advocacy, and life planning [15]. Ideally, the transition team should include pediatric and adult physicians, pediatric and adult nurse practitioners, pediatric and adult social workers, an education coordinator, and a clinical psychologist [13, 15, 24]. A formal meeting initiated by the pediatric care team to introduce the patient and parents to the adult care team

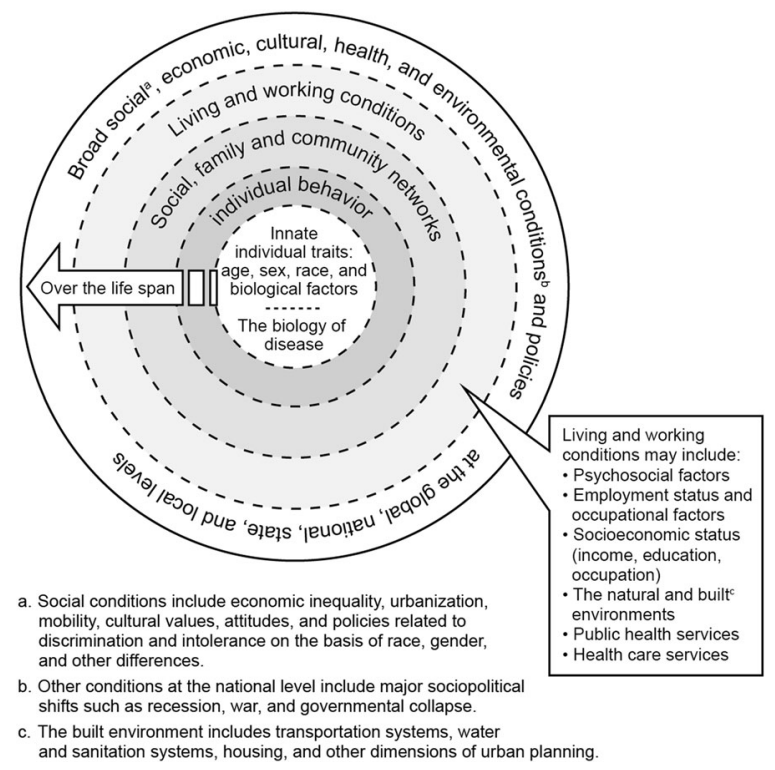

Fig. 2 Institute of Medicine's model of the multiple determinants of health [56]. Reprinted with permission from Centers for Disease Control and Prevention, Liburd and Sniezek [58] 
may further enhance the transition process [16, 24]. Developmental age, rather than chronological age, should guide transition as much as possible, as factors such as delayed neurocognitive development may mean that a patient is not ready to transition from pediatric care to adult care at 18 years of age $[15,24]$.

One example of such a program is Guy's and St. Thomas' Hospital in the United Kingdom, an institution that cares for more than 500 individuals with SCD. Transition of care typically occurs when patients are 16-18 years of age, but timing is flexible and patient focused [58]. The clinic also has biannual transition open days, during which young patients and their families may ask questions about the differences between pediatric and adult care and can learn about the expectations and preparation needs for the transition process [58]. Pediatric nursing and psychological teams can bridge care during the transition period by developing a plan that identifies each patient's unique health, social, educational, and developmental needs.

Another example of this approach is the CHRISTUS Santa Rosa Children's Hospital in San Antonio, Texas, where patients and their families are first introduced to the transition program at a newborn's initial visit or on transfer from another clinic to ensure a continuum of care [67]. At 13 years of age, patient and parent education begins with the provision of a binder that includes skill checklists, appointment and problem-reporting tracking sheets, and additional educational resources. By 18 years of age (or depending on developmental age, usually at an average of 21 years), patients are considered to have transitioned [67]. Evaluation of the efficacy of such transition programs will be essential to identify best practices that can be shared with other providers.

Both the day hospital and chronic care models are exemplars of a biopsychosocial and multidisciplinary approach that may be especially effective for transitioning young adults with SCD. The day hospital model provides an alternative to inpatient care. In this model, patients with SCD with painful but otherwise uncomplicated vaso-occlusive episodes can obtain care in an outpatient infusion center or SCD-specific day hospital setting where the staff is knowledgeable about the disease [68]. In the chronic care model, a "medical home" or family-centered practice that delivers preventive care, acute illness management, and chronic condition management for pediatric patients and coordinates patient support and transition services could be adopted [14, 69]. A similar, coordinated system of care that allows holistic treatment of patient and family is needed for both adult and adolescent patients with SCD.

Treatment programs for other chronic illnesses (e.g., hemophilia and cystic fibrosis) can guide the development of biopsychosocial and multidisciplinary SCD programs. For example, there are more than 130 hemophilia treatment centers in the United States that not only treat individuals with hemophilia, but also provide continual medical and psychosocial support throughout their lifetimes [70]. These comprehensive, multidisciplinary care programs have resulted in improved health outcomes for young adult patients. In addition, practice models that incorporate patient registries have been effective in helping practitioners monitor key health outcomes and the effectiveness of treatment protocols over time.

Collaboratives, such as the National Initiative for Childrens' Healthcare Quality project known as WISCH (Working to Improve Sickle Cell Healthcare), are focused on improving quality of care for patients with SCD during their entire lifetime, including 
patients who are in the process of transitioning to adult care [19]. Teams consisting of health care providers, patients, hematologists, nurses, and others aim to implement timely acute care management, better coordination of care, better transition from pediatric to adult care, improved screening, counseling, and education for individuals with SCD, and enhanced education for providers on treating, assessing, and monitoring SCD [19]. Recently, the National Institute for Children's Health Quality developed the Curriculum for Transition from Pediatric to Adult Medical Care for Adolescents with SCD, which provides a biopsychosocial framework for the issues to be addressed during the transition period for adolescents and young adults with SCD [19].

\section{CONCLUSIONS}

Key issues for patients with SCD who are transitioning to adult care include biological, psychosocial, and sociological factors that require specialist care from multiple disciplines. Therefore, a biopsychosocially oriented, multidisciplinary model should be used to facilitate the successful transition of all pediatric patients with SCD to adult care. This will enable adolescents to fully assume adult roles, actively participate in all aspects of their health care, and take responsibility for the management of their chronic disease. While there are some centers with these types of programs, such programs are still needed at the majority of centers delivering care to young adult patients with SCD. Collaboratives are working toward improving SCD care across patient lifetimes, which may include utilization of a multidisciplinary approach that adapts to the patient needs. Evaluation and monitoring of the impact and efficacy of biopsychosocial models in comparison to traditional models will provide additional insights into effective methods to improve care during the transition process and health outcomes in young adulthood.

\section{ACKNOWLEDGMENTS}

All named authors meet the International Committee of Medical Journal Editors (ICMJE) criteria for authorship for this manuscript, take responsibility for the integrity of the work as a whole, and have given final approval to the version to be published. Medical writing in the preparation of this manuscript was provided by Susan M. Kaup, PhD, and Tara Beers Gibson, PhD, of Evidence Scientific Solutions; editorial assistance was provided by Phase Five Communications. Support for this assistance was funded by Novartis Pharmaceuticals Corporation. The article processing charges associated with this publication were funded by Novartis Pharmaceuticals Corporation. The authors received no direct funding from Novartis Pharmaceuticals Corporation. The authors would like to thank our patients and their families, and our transition team, for helping us to identify and begin to address salient issues for transitioning adolescents and young adults with sickle-cell disease. Dr. Crosby's time was supported in part by Grant \# K07HL108720, funded by the National Institutes of Health (NIH), National Heart, Lung, and Blood Institute (NHLBI). Dr. Quinn's time was supported in part by Grant \# U01HL117709, funded by the NIH, NHLBI. The content is solely the responsibility of the authors and does not necessarily represent the official views of the NIH. 
Conflict of interest. Lori E. Crosby, Charles T. Quinn, and Karen A. Kalinyak declare that they have no conflict of interest.

Compliance with ethics guidelines. The analysis in this article is based on previously conducted studies, and does not involve any new studies of human or animal subjects performed by any of the authors.

Open Access. This article is distributed under the terms of the Creative Commons Attribution Noncommercial License which permits any noncommercial use, distribution, and reproduction in any medium, provided the original author(s) and the source are credited.

\section{REFERENCES}

1. Hamideh D, Alvarez O. Sickle cell disease related mortality in the United States (1999-2009). Pediatr Blood Cancer. 2013;60:1482-6.

2. Lanzkron S, Carroll CP, Haywood C Jr. Mortality rates and age at death from sickle cell disease: U.S., 1979-2005. Public Health Rep. 2013;128:110-6.

3. Yanni E, Grosse SD, Yang Q, Olney RS. Trends in pediatric sickle cell disease-related mortality in the United States, 1983-2002. J Pediatr. 2009; 154:541-5.

4. Hassell KL. Population estimates of sickle cell disease in the U.S. Am J Prev Med. 2010;38(4 Suppl):S512-21.

5. Quinn CT, Rogers ZR, McCavit TL, Buchanan GR. Improved survival of children and adolescents with sickle cell disease. Blood. 2010;115:3447-52.

6. Wierenga KJ, Hambleton IR, Lewis NA. Survival estimates for patients with homozygous sickle-cell disease in Jamaica: a clinic-based population study. Lancet. 2001;357:680-3.

7. Vichinsky EP. Comprehensive care in sickle cell disease: its impact on morbidity and mortality. Semin Hematol. 1991;28:220-6.

8. Streetly A, Latinovic R, Hall K, Henthorn J. Implementation of universal newborn bloodspot screening for sickle cell disease and other clinically significant haemoglobinopathies in England: screening results for 2005-7. J Clin Pathol. 2009;62:26-30.

9. Gaston MH, Verter JI, Woods G, et al. Prophylaxis with oral penicillin in children with sickle cell anemia. N Engl J Med. 1986;314:1593-9.

10. Adamkiewicz TV, Silk BJ, Howgate J, et al. Effectiveness of the 7-valent pneumococcal conjugate vaccine in children with sickle cell disease in the first decade of life. Pediatrics. 2008;121:562-9.

11. Steinberg $\mathrm{MH}$, Barton F, Castro O, et al. Effect of hydroxyurea on mortality and morbidity in adult sickle cell anemia: risks and benefits up to 9 years of treatment. JAMA. 2003;289:1645-51.

12. Voskaridou E, Christoulas D, Bilalis A, et al. The effect of prolonged administration of hydroxyurea on morbidity and mortality in adult patients with sickle cell syndromes: results of a 17-year, singlecenter trial (LaSHS). Blood. 2010;115:2354-63.

13. Jordan L, Swerdlow P, Coates TD. Systematic review of transition from adolescent to adult care in patients with sickle cell disease. J Pediatr Hematol Oncol. 2013;35:165-9.

14. DeBaun MR, Telfair J. Transition and sickle cell disease. Pediatrics. 2012;130:926-35.

15. Treadwell M, Telfair J, Gibson RW, Johnson S, Osunkwo I. Transition from pediatric to adult care in sickle cell disease: establishing evidence-based practice and directions for research. Am J Hematol. 2011;86:116-20.

16. Lebensburger JD, Bemrich-Stolz CJ, Howard TH. Barriers in transition from pediatrics to adult medicine in sickle cell anemia. J Blood Med. 2012;3:105-12.

17. Okumura MJ, Heisler M, Davis MM, Cabana MD, Demonner S, Kerr EA. Comfort of general internists and general pediatricians in providing care for young adults with chronic illnesses of childhood. J Gen Intern Med. 2008;23:1621-7.

18. Rosen DS, Blum RW, Britto M, Sawyer SM, Siegel DM. Transition to adult health care for adolescents and young adults with chronic conditions: position paper of the Society for Adolescent Medicine. J Adolesc Health. 2003;33:309-11.

19. Brown RT, editor. Comprehensive handbook of childhood cancer and sickle cell disease: a biopsychosocial approach. New York: Oxford University Press; 2006. 
20. Nash KB, Telfair J. Sickle cell disease: a biopsychosocial model. In: Livingston I, editor. Handbook of Black American health: the mosaic of conditions, issues, policies, and prospects. Westport: Greenwood Press; 1994. p. 123-39.

21. Taylor LE, Stotts NA, Humphreys J, Treadwell MJ, Miaskowski C. A biopsychosocial-spiritual model of chronic pain in adults with sickle cell disease. Pain Manag Nurs. 2013;14:287-301.

22. Ballas SK, Kesen MR, Goldberg MF, et al. Beyond the definitions of the phenotypic complications of sickle cell disease: an update on management. ScientificWorldJournal. 2012;2012:949535.

23. Ballas SK, Lieff S, Benjamin LJ, et al. Definitions of the phenotypic manifestations of sickle cell disease. Am J Hematol. 2010;85:6-13.

24. Brousseau DC, Owens PL, Mosso AL, Panepinto JA, Steiner CA. Acute care utilization and rehospitalizations for sickle cell disease. JAMA. 2010;303:1288-94.

25. Adams RJ, Brambilla D. Discontinuing prophylactic transfusions used to prevent stroke in sickle cell disease. N Engl J Med. 2005;353:2769-78.

26. Ware RE, Helms RW. Stroke with transfusions changing to hydroxyurea (SWiTCH). Blood. 2012;119:3925-32.

27. Knight-Madden JM, Forrester TS, Lewis NA, Greenough A. Asthma in children with sickle cell disease and its association with acute chest syndrome. Thorax. 2005;60:206-10.

28. Sharpe CC, Thein SL. Sickle cell nephropathy-a practical approach. Br J Haematol. 2011;155:287-97.

29. Rogers ZR. Priapism in sickle cell disease. Hematol Oncol Clin N Am. 2005;19:917-28 (viii).

30. Porter JB, Evangeli M. Challenges of adherence and persistence with iron chelation therapy. Int $\mathrm{J}$ Hematol. 2011;94:453-60.

31. Chen E, Cole SW, Kato PM. A review of empirically supported psychosocial interventions for pain and adherence outcomes in sickle cell disease. J Pediatr Psychol. 2004;29:197-209.

32. Wang WC. The pathophysiology, prevention, and treatment of stroke in sickle cell disease. Curr Opin Hematol. 2007;14:191-7.

33. Jordan LC, Casella JF, DeBaun MR. Prospects for primary stroke prevention in children with sickle cell anaemia. Br J Haematol. 2012;157:14-25.
34. Aygun B, Wruck LM, Schultz WH, et al. Chronic transfusion practices for prevention of primary stroke in children with sickle cell anemia and abnormal TCD velocities. Am J Hematol. 2012;87:428-30.

35. NIH ends transcranial doppler (TCD) with transfusions changing to hydroxyurea (TWiTCH) clinical trial due to early results. National Institutes of Health website. http://www.nih.gov/news/health/ nov2014/nhlbi-19.htm. Accessed Dec 2, 2014.

36. Howard J, Woodhead T, Musumadi L, Martell A, Inusa BP. Moving young people with sickle cell disease from paediatric to adult services. $\mathrm{Br} \mathrm{J}$ Hosp Med (Lond). 2010;71:310-4.

37. Adams RJ, McKie VC, Brambilla D, et al. Stroke prevention trial in sickle cell anemia. Control Clin Trials. 1998;19:110-29.

38. Ohene-Frempong K, Weiner SJ, Sleeper LA, et al. Cerebrovascular accidents in sickle cell disease: rates and risk factors. Blood. 1998;91:288-94.

39. DeBaun MR, Armstrong FD, McKinstry RC, Ware RE, Vichinsky E, Kirkham FJ. Silent cerebral infarcts: a review on a prevalent and progressive cause of neurologic injury in sickle cell anemia. Blood. 2012;119:4587-96.

40. Pegelow $\mathrm{CH}$, Macklin EA, Moser FG, et al. Longitudinal changes in brain magnetic resonance imaging findings in children with sickle cell disease. Blood. 2002;99:3014-8.

41. Vichinsky EP, Neumayr LD, Gold JI, et al. Neuropsychological dysfunction and neuroimaging abnormalities in neurologically intact adults with sickle cell anemia. JAMA. 2010;303:1823-31.

42. Kugler S, Anderson B, Cross D, et al. Abnormal cranial magnetic resonance imaging scans in sicklecell disease. Neurological correlates and clinical implications. Arch Neurol. 1993;50:629-35.

43. Quinn CT, McKinstry RC, Dowling MM, et al. Acute silent cerebral ischemic events in children with sickle cell anemia. JAMA Neurol. 2013;70:58-65.

44. DeBaun MR, Gordon M, McKinstry RC, et al. Controlled trial of transfusions for silent cerebral infarcts in sickle cell anemia. $\mathrm{N}$ Engl J Med. 2014;371:699-710.

45. Halfon N, Hochstein M. Life course health development: an integrated framework for developing health, policy, and research. Milbank Q. 2002;80:433-79 (iii). 
46. King AA, Strouse JJ, Rodeghier MJ, et al. Parent education and biologic factors influence on cognition in sickle cell anemia. Am J Hematol. 2014;89:162-7.

47. DeBaun MR, Sarnaik SA, Rodeghier MJ, et al. Associated risk factors for silent cerebral infarcts in sickle cell anemia: low baseline hemoglobin, sex, and relative high systolic blood pressure. Blood. 2012;119:3684-90.

48. Dale JC, Cochran CJ, Roy L, Jernigan E, Buchanan GR. Health-related quality of life in children and adolescents with sickle cell disease. J Pediatr Health Care. 2011;25:208-15.

49. Telfair J, Myers J, Drezner S. Transfer as a component of the transition of adolescents with sickle cell disease to adult care: adolescent, adult, and parent perspectives. J Adolesc Health. 1994;15:558-65.

50. McPherson M, Thaniel L, Minniti CP. Transition of patients with sickle cell disease from pediatric to adult care: assessing patient readiness. Pediatr Blood Cancer. 2009;52:838-41.

51. Wojciechowski EA, Hurtig A, Dorn L. A natural history study of adolescents and young adults with sickle cell disease as they transfer to adult care: a need for case management services. J Pediatr Nurs. 2002;17:18-27.

52. Wilkie DJ, Johnson B, Mack AK, Labotka R, Molokie RE. Sickle cell disease: an opportunity for palliative care across the life span. Nurs Clin N Am. 2010;45:375-97.

53. Hauser ES, Dorn L. Transitioning adolescents with sickle cell disease to adult-centered care. Pediatr Nurs. 1999;25:479-88.

54. Eccleston C, Palermo TM, de C Williams AC, et al. Psychological therapies for the management of chronic and recurrent pain in children and adolescents. Cochrane Database Syst Rev. 2012;12:CD003968.

55. Thornburg CD, Calatroni A, Telen M, Kemper AR. Adherence to hydroxyurea therapy in children with sickle cell anemia. J Pediatr. 2010;156:415-9.

56. Ware RE. How I use hydroxyurea to treat young patients with sickle cell anemia. Blood. 2010;115:5300-11.

57. Strouse JJ, Jordan LC, Lanzkron S, Casella JF. The excess burden of stroke in hospitalized adults with sickle cell disease. Am J Hematol. 2009;84:548-52.

58. Liburd LC, Sniezek JE. Changing times: new possibilities for community health and well-being. Prev Chronic Dis. 2007;4:A73.
59. King AA, DeBaun MR, White DA. Need for cognitive rehabilitation for children with sickle cell disease and strokes. Expert Rev Neurother. 2008;8:291-6.

60. Bediako SM. Predictors of employment status among African Americans with sickle cell disease. J Health Care Poor Underserved. 2010;21:1124-37.

61. Key features of the Affordable Care Act by year. U.S. Department of Health \& Human Services Web site. http://www.hhs.gov/healthcare/facts/timeline/time line-text.html. Accessed Sept 18, 2014.

62. American Academy of Pediatrics. Health supervision for children with sickle cell disease. Pediatrics. 2002;109:526-35.

63. Okumura MJ, Kerr EA, Cabana MD, Davis MM, Demonner S, Heisler M. Physician views on barriers to primary care for young adults with childhoodonset chronic disease. Pediatrics. 2010;125:e748-54.

64. Registry and surveillance system for hemoglobinopathies (RuSH). Centers for Disease Control and Prevention Web site. http://www.cdc. gov/ncbddd/hemoglobinopathies/documents/rush factsheet2010.pdf. Accessed Oct 30, 2014.

65. National Institutes of Health, National Heart, Lung, and Blood Institute. The management of sickle cell disease. NIH Publication No. 02-2117; 2002.

66. Doulton DM. From cradle to commencement: transitioning pediatric sickle cell disease patients to adult providers. J Pediatr Oncol Nurs. 2010;27:119-23.

67. Jordan L. Day hospital reduces inpatient length of stay and emergency department visits for patients with sickle cell anemia. https://innovations.ahrq. gov/profiles/day-hospital-reduces-inpatient-lengthstay-and-emergency-department-visits-patientssickle.

68. American Academy of Pediatrics, American Academy of Family Physicians, and American College of Physicians, Transitions Clinical Report Authoring Group. Supporting the health care transition from adolescence to adulthood in the medical home. Pediatrics. 2011;128:182-200.

69. Grosse SD, Schechter MS, Kulkarni R, Lloyd-Puryear MA, Strickland B, Trevathan E. Models of comprehensive multidisciplinary care for individuals in the United States with genetic disorders. Pediatrics. 2009;123:407-12.

70. Topic: sickle cell disease. National Institute for Children's Health Quality Web site. http://www. nichq.org/sitecore/content/sickle-cell-disease/sicklecell-disease. Accessed 24 Mar 2015. 